\title{
TRABALHO DOCENTE E SAÚDE: UM ESTUDO COM PROFESSORES DA EDUCAÇÃO BÁSICA DO SUDOESTE GOIANO
}

\author{
Regisnei Aparecido Oliveira Silva ${ }^{1}$ \\ Lídia Andreu Guillo ${ }^{2}$
}

\begin{abstract}
RESUMO
O trabalho docente tem sofrido inúmeras mudanças nas últimas décadas que repercute negativamente sobre a saúde do professor e a qualidade do ensino. Nesse contexto torna-se necessária a realização de pesquisas com essa temática para conhecer a realidade do trabalho do professor na Educação Básica e apontar caminhos para a superação dos problemas. Assim, o presente estudo teve por objetivo verificar a relação entre condições de trabalho e a saúde autorrelatada dos docentes do sexo masculino da rede pública estadual de Educação Básica em uma cidade do sudoeste goiano. O estudo foi realizado com 20 professores de escolas públicas estaduais que se dispuseram participar da pesquisa com autorização por meio de Termo de Consentimento Livre e Esclarecido (TCLE). Para a coleta de dados foi utilizado formulário de identificação das condições de trabalho e saúde. Os resultados mostram inúmeros fatores que caracterizam a realidade vivenciada pelos sujeitos investigados, identificando aspectos importantes que podem caracterizar a relação entre as condições de trabalho e saúde dos professores. Esses aspectos permitem inferir que as condições de trabalho docente interferem na saúde dos professores, gerando inúmeros problemas de natureza física e psíquica.
\end{abstract}

Palavras-chave: Condições de trabalho. Saúde docente. Educação básica.

\section{TEACHERS' WORK AND HEALTH: A STUDY WITH TEACHERS OF BASIC EDUCATION OF THE SOUTHWEST GOIÁS}

\begin{abstract}
The teaching profession has undergone numerous changes in recent decades, thus reflecting negatively on the health of teachers and in the quality of education. In this context, it becomes necessary to carry out research on this topic to know the reality of the teacher's work in basic education and point out ways to overcome the problems. Thus, this study was aimed to verify the relationship between working conditions and self-reported health of male teachers of public schools of basic education in a city in southwest Goias, Brazil. The study was conducted with 20 teachers from public schools who expressed interest to participate in the research. Thus they signed a Free and Informed Consent (FC) form. For data collection was

\footnotetext{
${ }^{1}$ Mestre em Educação pela Universidade Federal de Mato Grosso. Doutorando do Programa de Pós-graduação em Ciências da Saúde da Universidade Federal de Goiás (UFG). Professor de Estágio e Prática de Ensino do Curso de Biologia da UFG. Email: regisneioliveira@gmail.com

${ }^{2}$ Doutora em Ciências Biológicas pela Universidade de São Paulo. Professora Titular da Universidade Federal de Goiás- UFG. Email: lidia.guillo@ gmail.com
} 


\section{-4Bunerariuls D Revista Eletrônica da Pós-Grâduação 20 \\ v. 11, n. 2,2015

used forms of identification of work and health conditions. The results show several factors that characterize the reality experienced by the teachers. Thus identifying important aspects that can characterize the relationship between working conditions and health of teachers. These features allow us to infer that the working conditions of teachers can influence their health, creating numerous problems of physical and psychological nature.

Keywords: Work conditions. Teachers' health. Basic education.

\section{INTRODUÇÃO}

A noção de condições de trabalho designa o conjunto de recursos que possibilitam a realização do trabalho, envolvendo as instalações físicas, materiais e meios de realização das atividades. Refere-se também a um conjunto que inclui relações, as quais dizem respeito ao processo de trabalho e às condições de emprego (formas de contratação, remuneração, carreira). Contudo, as condições de trabalho não se restringem ao plano do posto ou local de trabalho ou à realização em si do processo de trabalho, mas diz respeito também às relações de emprego. Nesse sentido a relação do trabalho docente com o ambiente educativo vai além da sala de aula, envolvendo atividades de gestão da organização escolar e demais ações que garantam a eficácia do ensino e funcionamento da escola (OLIVEIRA; ASSUNÇÃO, 2010).

Todo esse processo educativo tem tido sua dinâmica alterada no decorrer dos tempos, conforme as mudanças sociais, políticas e econômicas. No Brasil as políticas educacionais implantadas nas últimas décadas, tomando como marco inicial a nova LDB (Lei de Diretrizes e Bases da Educação Nacional - Lei nº 9394/96), resultaram em mudanças substanciais nos sistemas de ensino e na compreensão das características do trabalho docente. As escolas passaram a organizar-se no sentido das demandas por maior atendimento, aumentando matrículas, turmas, número de alunos e modalidade de ensino. Essa nova forma de organização culminou na ampliação das tarefas assumidas pela escola e consequentemente nas funções do trabalho docente. À medida que se tornam mais complexas as demandas às quais as escolas devem responder, também se complexificam as atividades dos docentes (ASSUNÇÃO; OLIVEIRA, 2009).

Para Assunção e Oliveira (2009) esta situação provocou um fenômeno denominado intensificação do trabalho docente. A intensificação do trabalho é definida pelas autoras como o ato de fazer a mesma coisa mais rapidamente. Esse processo de intensificação provoca a degradação do trabalho não só em termos de qualidade da atividade, mas também 


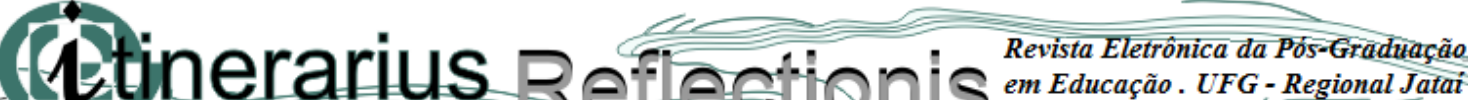 201

da qualidade do bem ou do serviço produzido. "Essas evidências sustentam as bases de um modelo explicativo para o processo de morbidade docente, calcado em determinantes ambientais e organizacionais, e suas influências sobre a atividade de trabalho" (p. 367).

A categoria de professores encontra-se exposta a riscos de doença, tanto física como psicossociais, ao defrontarem com situações cotidianas. Essas situações desequilibram as expectativas individuais do profissional, produzindo efeitos negativos nas atividades educacionais e em sua saúde. Desse modo, pode-se dizer que os docentes se configuram entre as principais categorias de profissionais expostas aos riscos psicossociais, decorrentes do modelo de trabalho (MORENO-JIMENEZ et. al. 2002).

Para Esteve (1999) entre o ideal da função de professor e as condições que o mercado de trabalho impõe, perdura um espaço de tensão que ocasiona um nível de estresse elevado, pressionando para baixo a eficácia da atividade docente. Diante desta situação o professor dispõe de estratégias de enfrentamento para adaptar-se à realidade. Este enfrentamento leva ao esgotamento dos recursos emocionais e como consequência a deterioração profissional, pessoal e problemas de saúde, principalmente, profissionais do gênero feminino que, além da jornada de trabalho escolar, possuem outra jornada de trabalho doméstico. Essa realidade tem sido apontada em pesquisa realizada por Areia e Guimarães (2004) com professores do estado de São Paulo, a qual destaca que os professores do gênero feminino apresentam maior chance de adoecerem que os professores do gênero masculino.

Sabe-se que a categoria docente é essencialmente feminina. No entanto, pesquisas apontam que o número de mulheres em relação aos homens que entram na profissão tem diminuído gradativamente ano a ano, ocorrendo um processo de "desfeminilização" da categoria, principalmente no Ensino Médio, nível de ensino em que, atualmente, já há quase uma igualdade de gêneros (BATISTA; CODO, 1999). A atuação de docentes do sexo masculino na Educação Básica é um fenômeno recente e crescente nos últimos anos que merece ser pesquisado.

Diante do contexto apresentado, o presente estudo objetivou discutir a relação entre condições de trabalho e a saúde dos docentes do sexo masculino da rede pública estadual de Educação Básica da cidade de Jataí-GO. 


\section{Atingrariulo Revista Eletrônica da Pós-Gráduação em Educação. UFG - Regional Jatai ISSN: 1807-9342 v. 11, n. 2,2015}

\section{FUNDAMENTAÇÃO TEÓRICA}

Desde a antiguidade aos dias atuais, o trabalho docente ocupa uma posição central na sociedade. Tal centralidade decorre do fato de que o professor se constitui como agente cultural, formador, capaz de produzir novos conhecimentos, de inovar e ser inovado (CANDAU, 2006). Sob essa perspectiva, Nóvoa (2010) descreve que os professores reaparecem, neste início de século XXI, como elementos insubstituíveis não só na promoção de aprendizagens, mas também na construção de processos de inclusão que respondam aos desafios da diversidade e no desenvolvimento de métodos apropriados de utilização das novas tecnologias.

O trabalho docente transcende os espaços da esfera escolar, uma vez que novos desafios são apresentados a todo o momento e as respostas obtidas já não atendem aos anseios da sociedade. Nesse contexto, estudos realizados por Esteve (1999); Naujorks (2002); Gasparini, Barreto e Assunção (2005); Assunção e Oliveira (2009) apontam que as novas demandas chegaram à escola pública sem que esta tivesse condições reais de atendimento frente à nova situação, gerando mal estar e consequente adoecimento. O ensino básico, em especial, tem atribuído inúmeras funções aos professores, muitas vezes além de sua carga horária de trabalho, dando continuidade às atividades em casa e nos finais de semana, sobrecarregando muitas vezes os profissionais.

A realidade das condições de trabalho dos docentes na atualidade é reportada por muitos pesquisadores como um processo de precarização do trabalho (ALVES, 2012; ASSUNÇÃO; OLIVEIRA, 2009; BOSI, 2007; OLIVEIRA, 2004) e tem-se constituído em um rico campo temático multidisciplinar para investigação científica. O processo de precarização do trabalho docente pode ser observado no interior das políticas educacionais implantadas nas últimas décadas, orientada por mudanças curriculares, de formação e atuação do professor. Uma das características dessas políticas é a mudança de perfil do trabalho do professor da Educação Básica ao ter que assumir inúmeras funções no campo educacional. Essa situação é observada por Oliveira (2006):

Os professores são, em geral, considerados os principais responsáveis pelo desempenho dos alunos, da escola e do sistema, no contexto atual de reformas educacionais e de uma nova regulação educativa. Diante das variadas funções que a escola pública assume, os professores encontram-se frequentemente diante da necessidade de responder às exigências que estão para além de sua formação. (p. 212). 


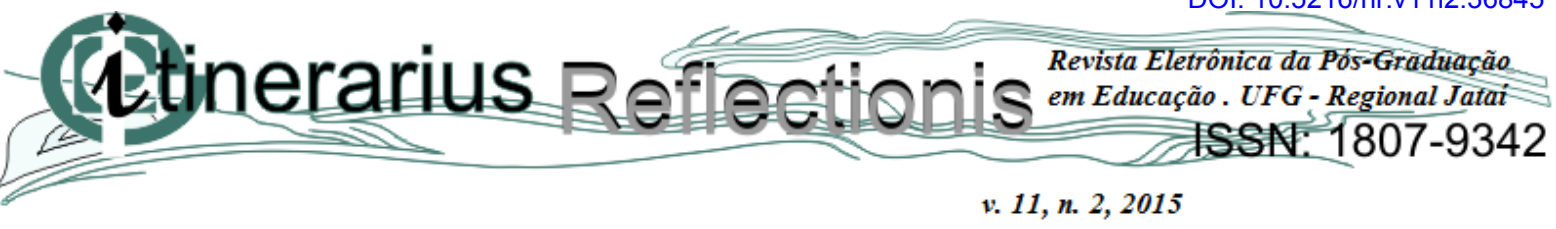

No Estado de Goiás, inúmeras ações podem ser caracterizadas como precarização do trabalho docente. As mais recentes estão associadas às condições de trabalho e questões salariais.

A carreira docente no estado de Goiás está amparada pelo Estatuto e Plano de Cargos e Vencimentos do Pessoal do Magistério Público Estadual da Educação Básica e Profissional (Lei ${ }^{\circ}$ 13. 909/2001) $)^{3}$. Nessa lei, a carreira docente organiza-se em níveis e referências e prevê a progressão vertical e horizontal. A progressão vertical compreende a passagem de níveis (PI, PII, PIII e PIV) já a progressão horizontal, por sua vez, efetua-se pela passagem entre diferentes referências (A, B, C, D, E, F, G) no mesmo nível. Nos termos da lei, a movimentação vertical se dará por titulação (habilitação) e a movimentação horizontal se dá por merecimento e na observância de algumas condições descritas no Art. 76: tempo de exercício, avaliação de desempenho, participação em programas ou cursos de capacitação.

O salário do professor no Estado de Goiás compreende vencimento básico e gratificações. Dentre as gratificações destaca-se a gratificação por desempenho, formação avançada e gratificação de estímulo à formação continuada. A gratificação por desempenho ocorre a partir da aprovação docente em avaliação, em interstício mínimo de três anos, com acréscimo de 10 até o máximo de $60 \%$ sobre o vencimento básico. É realizada anualmente pelas Secretarias da Educação e de Gestão e Planejamento. A gratificação por formação avançada ocorre após realização de mestrado e doutorado e compreende um acréscimo sobre o vencimento básico de $40 \%$ e $50 \%$ respectivamente. A gratificação de estímulo à formação continuada é concedida ao professor em efetivo exercício de atividades na área pedagógica mediante apresentação de certificados de cursos na área educacional, observado o interesse da Secretaria de Estado da Educação e com critérios definidos pelo seu titular conjuntamente com o da Secretaria de Estado de Gestão e Planejamento (Art. 63 E e F - Lei 17.665/2012).

O regime de trabalho do professor da Educação Básica do Estado de Goiás encontra-se dividido em carga horária semanal de 20, 30 e 40 horas. Do total da carga horária, $30 \%$ é definida como hora-atividade, caracterizada por ações de planejamento, atendimento a alunos, formação continuada, devendo ser cumpridas preferencialmente no horário escolar. O percentual de horas-atividades se destina tanto aos professores concursados quanto aos de contratos temporário.

\footnotetext{
${ }^{3}$ A Lei 13.909/2001 foi alterada em diversos pontos pelas Leis $\mathrm{n}^{\mathrm{o}}$ 17.039/2010; 16.544/2009; 14.678/2004 e $17.402 / 2011$.
} 


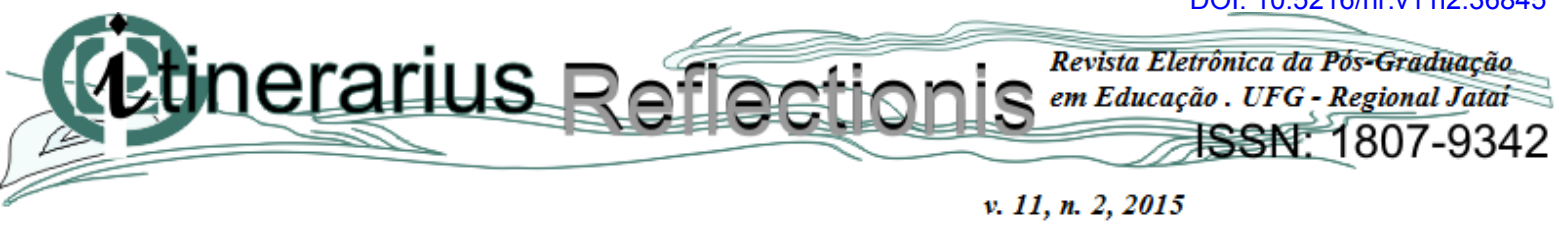

Partindo desse princípio, Silva (2012) destaca que o alto número de professores em contrato temporário e profissionais concursados em desvio de função é outro fator que concorre à precarização do trabalho docente. Dentre os aspectos de precarização do trabalho docente descrito pelo autor destaca-se também a rotatividade no exercício da profissão. Em pesquisa realizada no Estado de Goiás identificou-se que 55\% dos professores trabalham, no máximo, até três anos na mesma unidade escolar. Essa rotatividade traz péssimas consequências ao trabalho coletivo, como práticas interdisciplinares e ações democráticas que dependem de consonância entre os pares.

Ainda sobre o trabalho docente, foi implantada no Estado de Goiás, por intermédio da Lei n 17.402 de 06 de setembro de 2011, uma política de "Bônus de Estímulo à Regência”, para professores em regência de classe e em exercício nas unidades escolares pertencentes à rede estadual de ensino. Essa lei institui o bônus com base no percentual de faltas do docente durante o ano letivo.

Essa lei, além de provocar o isolamento e estimular a competição entre os professores, minimiza as relações solidárias e ações de trabalhos coletivos na unidade escolar. Tal situação reforça os inúmeros estudos que têm constatado uma progressiva responsabilização dos professores, por parte dos poderes públicos, pelo baixo desempenho dos alunos nos exames nacionais, contribuindo de maneira contundente para acirrar o processo de intensificação do trabalho docente (OLIVEIRA, 2012 ).

Essa política de bonificação pode contribuir para o descontentamento da maioria dos profissionais da educação, pois cresce o desprestígio da categoria ao associar o trabalho docente com a distribuição de "prêmios" em dinheiro e resultando na intensificação do trabalho. Essa situação tem reforçado o controle de desempenho dos professores, frustrando a categoria, na medida em que esta se sente desestimulada a continuar na profissão.

Os problemas da Educação Básica percebidos tanto no Brasil como no Estado de Goiás provocam o desestímulo à opção pela carreira docente, desse modo, a falta de professores faz com que os profissionais em exercício atuem em mais de um turno e em mais de uma escola. Além disso, os baixos salários levam à necessidade de aumentar a renda fazendo com que os professores busquem outras atividades que lhes tomam tempo e dedicação, comprometendo as atividades da escola.

Diante desse contexto, a categoria de professores, principalmente os docentes da Educação Básica, encontra-se exposta a riscos psicossociais ao defrontar com situações adversas em seu cotidiano. Esta situação tem levado os professores ao adoecimento físico e 


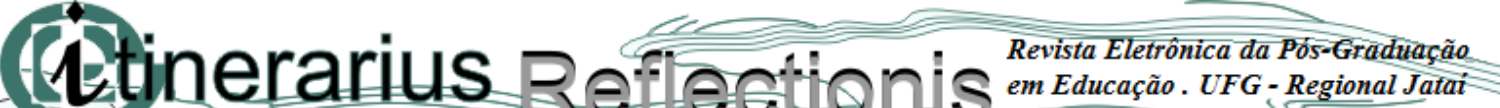 2 Educação. UFG Regional Jatat \\ v. 11, n. 2,2015}

psíquico, gerando mal-estar na profissão. Corroborando essa discussão, Nóvoa (1999) destaca que há muito tempo os professores vêm sofrendo de uma situação de mal-estar na profissão, que causa desmotivação pessoal com a docência, abandono, insatisfação, indisposição, dentre outros sintomas que demonstram uma autodepreciação da carreira.

A imagem idealizada do professor, como uma figura modelo, que se coloca diante de grupos de alunos obtendo respeito e admiração dos próprios alunos e de toda a sociedade já não se faz presente nos dias atuais, levando a uma situação de mal-estar docente e inúmeras consequências para sua atuação profissional. Esse contexto remete-nos às ideias de Nunes Sobrinho (2012), ao descrever que a dissociação entre o trabalho prescrito e o trabalho real gera um efeito negativo sobre a saúde e qualidade de vida do professor. Naujorks (2002) argumenta que a docência é uma das profissões que mais causa desgaste físico e emocional. Para a autora, esse trabalho, que poderia ser uma fonte de realização pessoal e profissional, torna-se frustrante e todas as situações novas que poderiam servir como motivação, passam a ser uma ameaça temida e, portanto, evitada. Um dos estudiosos da relação do trabalho com as condições de saúde docente é J. C. Dejours que, em diversos estudos sobre a temática, afirma que o trabalho pode tornar-se fonte de tensão e de desprazer, gerando um aumento da carga psíquica $^{4}$, dando origem ao sofrimento e à patologia. Por outro lado, o trabalho também pode ser fonte de prazer e realização pessoal. Para o autor, o sofrimento é definido a partir de alguns fatores como cansaço, desânimo e descontentamento com o trabalho (DEJOURS, 2015). Esses aspectos têm sido marca constante na vida cotidiana dos professores nas escolas brasileiras.

\section{PROCEDIMENTOS METODOLÓGICOS}

A pesquisa foi caracterizada como Estudo de caso descritivo com abordagem quantitativa. Esta abordagem é sugerida por Günther (2006), ao destacar que num estudo de caso é possível utilizar tanto procedimentos qualitativos quanto quantitativos. O estudo de caso, conforme Gil (2008) consiste em um estudo profundo e exaustivo de um ou poucos objetos, de maneira que permita seu amplo e detalhado conhecimento.

O estudo foi realizado com vinte professores (de um total e 39) do sexo masculino que atuam em escolas da rede pública estadual de Educação Básica em uma cidade do

\footnotetext{
4 “ “...] resulta da confrontação do desejo do trabalhador à injunção do empregador contida na organização do trabalho" (DEJOURS, 1994 p. 28).
} 


\section{Mtinerariulo Revista Eletrônica da Pós-Gráduação em Educação. UFG - Regional Jatai 20 \\ v. 11, n. 2, 2015 SSA: 1807-9342}

Sudoeste goiano. Após aprovação do projeto pelo Comitê de Ética em Pesquisa (CEP) da Universidade Federal de Goiás (Parecer n. 609.308) e anuência da Subsecretaria Estadual de Educação, foi realizada a escolha dos professores. A escolha caracterizou-se por amostra de conveniência não probabilística, tendo como critério ser professor do sexo masculino da Educação Básica, com mínimo de um ano de atuação. Após a seleção os professores assinaram um Termo de Consentimento Livre e Esclarecido (TCLE).

A escolha pelo sexo masculino se deu por ser um grupo crescente nos últimos anos, pouco estudado e que, conforme literatura apresenta poucas situações de afastamento (BATISTA; CODO, 1999). Como instrumentos de coleta de dados, foram utilizados formulários de identificação das condições de trabalho e saúde, aplicados no final do primeiro bimestre letivo de 2014. O formulário permitiu estudar variáveis relacionadas ao trabalho e condições de saúde (idade, tempo de experiência, carga horária semanal, número de escolas, situação trabalhista, níveis de ensino, disciplinas de atuação, doenças ocupacionais acometidas, tempo de descanso, percepção de problemas do cotidiano). O referido formulário foi testado como pré-teste em apenas uma escola e, após reformulação, foi aplicado a todos os participantes.

Os dados provenientes dos formulários tiveram tratamento estatístico conforme programa de software Microsoft Office Excell 2010. As variáveis estudadas tiveram análise descritiva e distribuição da frequência absoluta e relativa.

\section{RESULTADOS E DISCUSSÃO}

Participaram da pesquisa 20 professores do sexo masculino da Educação Básica atuantes em cinco escolas públicas da rede estadual que oferecem o Ensino Fundamental e Médio. Entre eles, dois exercem a função de diretor, dois de coordenadores e os demais atuam como professores em atividades de sala de aula.

Sobre a formação identificou-se que todos são licenciados em diferentes áreas do conhecimento, oito possuem pós-graduação lato sensu e dois professores possuem o curso de mestrado. Percebe-se que a instituição cumpre as recomendações da LDB, lei Federal $n^{\circ}$. 9.394/1996, artigo 62, o qual faz referência à formação mínima dos professores para exercerem o magistério na Educação Básica: “a formação de docentes para atuar na educação básica far-se-á em nível superior, em curso de licenciatura, de graduação plena, em universidades e institutos superiores de educação" (BRASIL, 1996). 


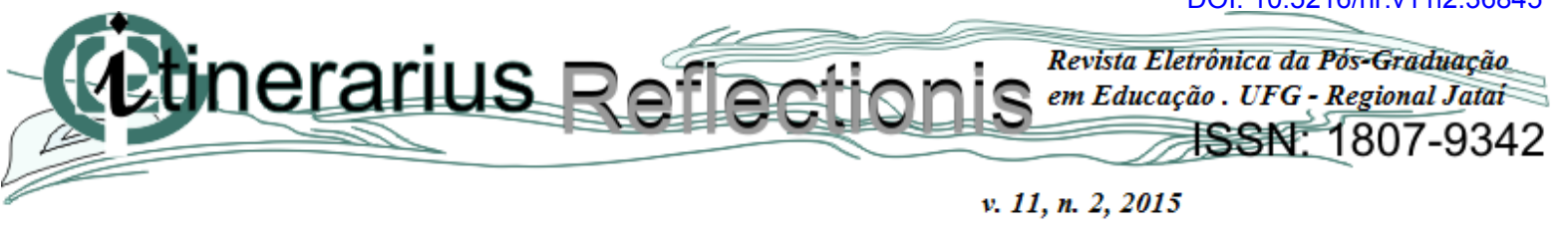

Conforme as variáveis estudadas, pode-se perceber que os professores pesquisados atuam em diferentes áreas do conhecimento, sendo 50\% atuantes nas Ciências da Natureza e matemática, $25 \%$ na área de linguagem e $25 \%$ em ciências humanas.

A maioria dos professores afirma que, além da formação inicial ou cursos de pósgraduação, não realizam formação contínua, caracterizada como cursos de atualização e/ou capacitação. Apenas dois professores disseram realizar cursos de formação contínua em espaços formativos como Universidades, Secretaria de Educação e outros espaços.

O tempo de atuação na docência é bastante variado entre os sujeitos pesquisados, indo de 1 a 30 anos. Para análise dos dados, o tempo de atuação foi organizado em quatro períodos: até 4 anos, 5 a 9 anos, 10 a 14 e 15 ou mais anos de atuação. Os dados mostram que a maioria dos professores (70\%) possui menos de 10 anos de docência, sugerindo que esses profissionais entraram no trabalho após a implantação da nova LDB e das Diretrizes Curriculares da Educação Básica e, portanto, já vivenciando os inúmeros problemas oriundos das mudanças no sistema educacional brasileiro. Essas mudanças, caracterizadas por transformações sociais, políticas e econômicas, exigiu das escolas e dos professores uma reorganização dos processos formativos e de trabalho, culminando em uma situação de precarização do trabalho, conforme abordagem teórica de ASSUNÇÃO; OLIVEIRA (2009).

Quanto à situação trabalhista a metade dos professores participantes da pesquisa está em regime de contrato temporário, enquanto os demais são efetivos. Este fato dificulta as relações de trabalho e o desenvolvimento de ações contínuas, revelando também a ausência de uma identidade profissional que pode comprometer o desenvolvimento de um trabalho coletivo e de qualidade no interior das escolas. Outro dado importante que revela um processo de precarização do trabalho docente é o número de escolas em que atuam. Entre os docentes investigados identificou-se que a maioria (70\%) atua em duas ou mais escolas.

Este cenário demonstra que os direitos trabalhistas dos professores não são compreendidos por muitos governos como condição essencial para a consolidação do processo de profissionalização docente (SILVA, 2012). Além do mais, a condição de atuar em lugares distintos em um mesmo dia leva o docente a percorrer distâncias consideráveis, mudar constantemente seu ambiente de trabalho e suas relações interpessoais, acarretando, com isso, desconforto físico e emocional.

Da mesma forma, a jornada de trabalho da maioria dos professores é extensa, muitas vezes atingindo 12 horas diárias, ou seja, três turnos. Metade dos professores tem uma 


\section{Motineraríls Revista Eletrônica da Pós-Gradtuação em Educação. UFG - Regional Jatai 20 v. 11, n. 2,2015 \\ SSN: 1807-9342}

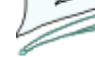

jornada de trabalho superior a 40 horas semanais, $45 \%$ possui jornada de 31 a 40 horas e apenas $5 \%$ dos pesquisados tem carga horária semanal de 20 horas.

A carga horária de trabalho docente compreende uma dimensão física e outra psíquica que influenciam direta e indiretamente a saúde e a vida dos professores (CRUZ et. al. 2010). Desse modo entende-se que o trabalho em excesso compromete a saúde física e mental desses profissionais ao mesmo tempo em que compromete as relações familiares e sociais.

\subsection{Condições de saúde e trabalho docente dos sujeitos pesquisados}

A relação entre o processo de trabalho docente e as condições em que o mesmo é realizado merece destaque por ser esta relação um fator de possível adoecimento tanto físico como mental dos professores. Os resultados da pesquisa realizada apontam inúmeros fatores que caracterizam a realidade vivenciada pelos sujeitos investigados, identificando aspectos importantes para o estudo da relação entre as condições de trabalho e saúde dos professores.

Durante a pesquisa foi apresentado a cada sujeito um formulário com uma lista de doenças, entre as quais deveria marcar aquelas que lhes tinham acometido. As doenças apresentadas são caracterizadas como ocupacionais que, de acordo com Costa (2009), são as moléstias de evolução lenta e progressiva, originárias de causa igualmente gradativa e durável, vinculadas às condições de trabalho. Entre as doenças marcadas pelos professores destaca-se o estresse, apontado por $70 \%$ dos professores. O estresse, embora seja caracterizado como um problema ligado ao sistema emocional foi apresentado em separado aos sujeitos. Pesquisa realizada no Brasil (CODO, 1999) revelou um nível elevado de estresse associado ao trabalho entre os docentes da Educação Básica. Outras doenças também de caráter emocional (depressão, ansiedade, nervosismo, crises de pânico) foram indicadas em menor percentual (25\%) pelos professores. Segundo a mesma pesquisa, essas doenças podem estar presentes na vida dos professores em decorrência do ritmo intenso de trabalho, a longa jornada de trabalho, tensão do ambiente de trabalho caracterizado por indisciplina e desinteresse dos alunos, bem como conflitos entre colegas de profissão.

Os problemas com a voz foram apontados como a terceira doença que mais acomete os professores pesquisados (55\%). A voz, como instrumento essencial do trabalho do professor, merece atenção e cuidado para que a mesma dê condições ao profissional de exercer seu trabalho de maneira eficaz. Esse problema pode ser agravado por diversos fatores como jornada de trabalho extensiva, acarretando o uso da voz por muitas horas seguidas; 


\section{Prinerariulo Revista Eletrônica da Pós-Gráduaçâa em Educação . UFG - Regional Jatai 坡 ISSN: 1807-9342 \\ v. 11, n. 2,2015}

número excessivo de alunos em sala de aula, fazendo-o aumentar a intensidade de sua voz para ser ouvido; condições físicas de trabalho inadequadas, como salas de aula mal projetadas, com problemas de acústica e ruído externo e interno; falta de informações sobre cuidados com a saúde vocal, tanto na formação profissional, quanto no decorrer da carreira (AMORIM, 2007). Esses mesmos fatores somados a outros (contato com muitas pessoas, pó de giz, pouca ventilação) são responsáveis pelos processos inflamatórios das vias respiratórias, apontados como um dos problemas de saúde que acomete um quarto (25\%) dos professores pesquisados.

As doenças musculoesqueléticas ocuparam o quarto lugar entre as citadas pelos professores (30\%). Essas doenças (dor nas costas, dor nas pernas, dor nos braços) podem ser ocasionadas pelos assentos inadequados ou ausência deles, longos períodos de pé para escrita no quadro, explicações de conteúdos ou atendimento aos alunos, carregar materiais didáticos e de apoio pedagógico (livros, computador, data-show), além da tensão do trabalho diário, que provoca problemas musculares e nas articulações (LIMA; LIMA-FILHO, 2009).

As doenças psicossomáticas, caracterizadas nessa pesquisa como gastrites, úlcera, enxaqueca foram apontada por $60 \%$ dos professores, sendo a segunda doença mais citada. Essas doenças são manifestadas, principalmente em pessoas que vivem ou trabalham em ambientes tensos, que exigem muito do estado psicossocial do indivíduo. Os professores se enquadram nesse perfil, pois estão constantemente submetidos a situações de esgotamento psíquico.

Doenças cardiovasculares, embora estivessem no formulário apresentado para os sujeitos não foram citadas, assim como os problemas relacionados aos acidentes de trabalho.

De um modo geral as doenças citadas revelam uma estreita relação com a sobrecarga ocupacional de trabalho dos indivíduos, ou seja, com a condição de realização de seu trabalho. No entanto, esses problemas de saúde nem sempre são motivos de afastamento dos professores de sua atividade profissional na escola. De todos os sujeitos participantes da pesquisa, quatorze docentes afirmaram nunca terem se afastado do trabalho para tratamento de doença. Outros seis (30\%), afirmam que se afastaram por um período que variou de 1 a 60 dias.

A relação do trabalho com a vida cotidiana do professor tem reflexo direto no bem estar de sua saúde, como apontam as pesquisas que dão suporte a esta discussão. Nos resultados obtidos pelo formulário aplicado aos professores pode-se perceber uma gama de fatores que devem ser levados em consideração, ao investigar a saúde docente e sua relação com as condições de trabalho. 


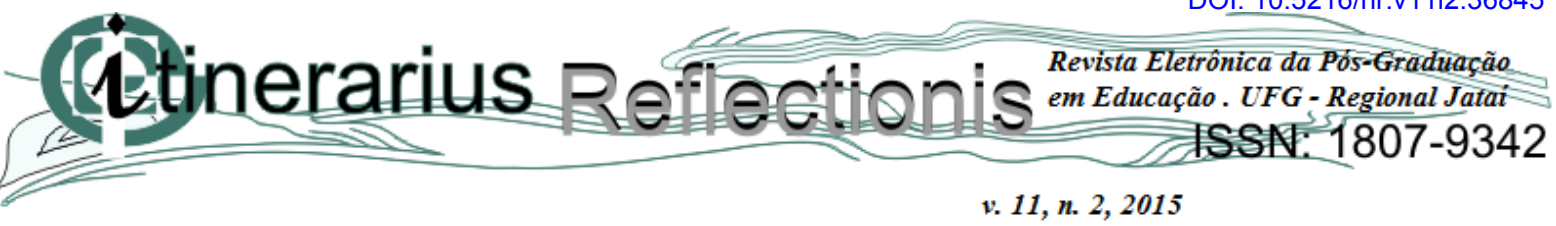

Todos os professores afirmaram levar trabalhos escolares para serem concluídos em casa, principalmente nos finais de semana. As opções "sempre" e "frequentemente" aparecem em $35 \%$ e $65 \%$ dos investigados respectivamente. Neste caso o trabalho "rouba" o tempo que deveria ser dedicado à família, gerando conflito entre a necessidade de trabalhar e a necessidade de dedicar um tempo de atenção ao cônjuge e filhos. "Se de um lado a necessidade de trabalhar, de outro a necessidade de se dedicar mais à família, à vida cotidiana com da casa, os filhos, o marido, as obrigações...; enfim, um conflito instalado, um paradoxo, uma angústia” (VASQUES-MENEZES; CODO; MEDEIROS, 1999 p. 281).

A situação apresentada compromete o descanso e o tempo livre para dedicar à família ou amigos. No entanto, observamos nos resultados que o pouco tempo livre dos professores é dedicado principalmente, a atividades com a família e amigos (75\%), assistir TV e descanso (60\%). Diante desse perfil de trabalho, os professores demonstraram não ter tempo para realização de atividades físicas e práticas esportivas, apontadas por aproximadamente metade dos participantes (55\%) o que compromete ainda mais as condições de saúde do trabalhador. Dentre os participantes que afirmam realizar atividades físicas, apenas três (15\%) realizam diariamente, $45 \%$ realizam com frequência e $40 \%$ raramente realizam.

Essas informações vão ao encontro do que afirma Robalino (2012) ao destacar que os professores dedicam enorme quantidade de horas de sua vida pessoal ao trabalho escolar, resultando em um excedente de horas trabalhadas sem remuneração. Desse modo, ao exercer o ofício docente, lhe sobra pouco tempo para o descanso, atividades de lazer ou atividades com amigos e familiares, comprometendo o tempo livre. É sabido que muitas vezes o trabalho docente invade o espaço doméstico culminando em um desajuste na profissão.

O lazer é determinado historicamente e possui uma característica imutável que é a busca pelo prazer e consequentemente a satisfação no trabalho. Desse modo, o lazer pode ser compreendido como um dos aspectos estruturantes da saúde física e mental, interferindo no processo saúde-doença do ser humano (CARVALHO; CUNHA, 2006).

A insatisfação no trabalho docente, apontada por alguns autores como "mal-estar docente $^{5 \%}$ pode interferir em seu bem estar na profissão, sendo fator determinante para algumas patologias, principalmente de cunho emocional. Nesta pesquisa, menos da metade (40\%) dos professores disseram estar satisfeitos com o trabalho que exercem. Outros $45 \%$ se

5 De acordo com Esteve (1999), mal-estar docente é um fenômeno social, que possui como agentes desencadeadores a desvalorização profissional, a violência, a indisciplina, entre outros fatores que podem promover uma crise de identidade em que o professor passa a se questionar sobre a sua escolha profissional e o próprio sentido da profissão. 


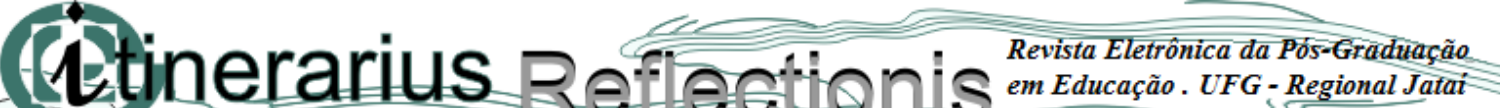 20 ISSN: 1807-9342 \\ v. 11, n. 2,2015}

mostraram indiferentes quanto a esta situação. Apenas $15 \%$ declararam completamente insatisfeitos e pretendem desistir da profissão. Esse dado reafirma os resultados obtidos por Oliveira (2006), em que destaca que os professores perderam a autoestima e muitos têm vergonha de declarar a profissão ou de falar do seu trabalho. Para a autora isso compromete o desempenho profissional e a saúde, advindo daí inúmeros casos de problemas mentais, sobretudo casos de burnout ${ }^{6}$.

Além dos problemas aventados, outras situações de cunho político e social, interferem diretamente no trabalho docente e consequentemente em sua condição de saúde. Os sujeitos pesquisados apontaram inúmeros problemas, destacando as condições salariais (80\%), desinteresse dos alunos pelo ensino (80\%) e ausência da família na escola (70\%). É importante destacar ainda os problemas recorrentes em muitas escolas do Brasil como indisciplina dos alunos (45\%), falta de materiais didáticos $(45 \%)$ e condições estruturais e ambientais da escola (45\%).

Como se vê, dentre os problemas que afetam a condição de trabalho do professor, a situação salarial da categoria compete com o desinteresse dos alunos pelo ensino. Os baixos salários levam o professor a ampliar sua carga horária de trabalho ou procurar outras fontes de renda, o que diminui o tempo para se dedicar à profissão, acompanhar os alunos, preparar aulas, dificuldade para se atualizar e consequentemente compromete sua saúde e o desenvolvimento de um trabalho de qualidade. Por outro lado o desinteresse dos alunos pelo ensino promove um desestímulo do professor para com a profissão. Muitas vezes os professores passam boa parte do tempo tentando convencer os alunos da importância e necessidade de estudar. Para isso, procuram inovar técnicas de ensino, muitas vezes sem grande sucesso, o que os deixam frustrados e acabam desistindo de seus esforços, levando-os à condições insatisfatórias de sua autoestima (FERREIRA, 2010).

O desinteresse do aluno pelo ensino e os problemas de indisciplina estão, muitas vezes, associados a outro problema citado pelos professores que merece destaque: a ausência da família na escola. Essa ausência compromete o trabalho docente, pois há uma compreensão entre os professores de que os pais ou responsáveis deveriam contribuir na educação escolar de seus filhos. Na medida em que essa parceria não funciona sobra para a escola toda a tarefa de educar, multiplicando o trabalho do professor.

\footnotetext{
${ }^{6}$ Burnout é uma síndrome através da qual o trabalhador perde o sentido da sua relação com o trabalho, de forma que as coisas já não o importam mais e qualquer esforço lhe parece inútil (CODO, 1999).
} 


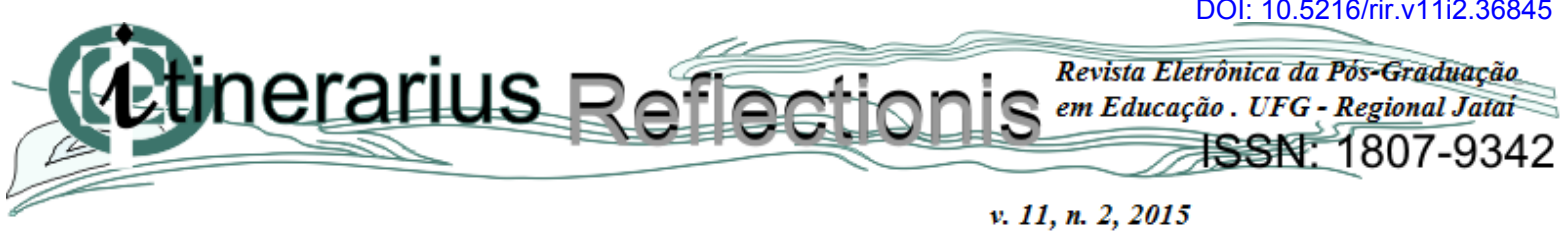

Na mesma medida, os problemas de violência e drogas nas escolas são apontados pelos professores como fator que interfere em sua situação de trabalho, caracterizando como uma fonte de tensão e insegurança. Esses problemas abalam o convívio harmonioso da comunidade escolar e, por vezes, professores sofrem ameaças a sua integridade física, comprometendo o seu bem estar no espaço de trabalho.

As condições estruturais e ambientais da escola não consideram o trabalho docente em sua totalidade, de modo que é comum nas escolas não existirem salas para a preparação de aulas, ausência de materiais didáticos ou espaços para descanso (ROBALINO, 2012). Nesse sentido, observa-se que na maioria das escolas sua arquitetura é pensada muito mais para garantir o silêncio e isolamento das turmas que integração do grupo, tornando ainda mais complexo o trabalho docente. Semelhante aspecto tem o pátio escolar, que não oferece as mínimas condições de vivência coletiva, quase sempre sem arborização, assentos ou áreas de lazer. O ambiente como espaço de convivência e de trabalho pode ter efeitos, mais ou menos, prejudiciais à saúde das pessoas (CAMPOS, 2006).

Quanto às relações que se estabelecem entre colegas, a pesquisa não revelou problemas que comprometem o trabalho docente, sendo apontados por apenas um sujeito. No entanto, pesquisas têm mostrado que há uma complexidade no relacionamento interpessoal entre os docentes de um mesmo estabelecimento de ensino que por vezes podem gerar conflitos em suas práticas cotidianas. É preciso compreender as difíceis e complexas relações existentes entre os professores e a gestão escolar, professores e alunos, professores e professores, como elementos necessários para compreensão da intricada rede envolvendo a dinâmica da organização do processo de trabalho na escola e o adoecimento docente. (BORGES, 2011).

Diante do exposto, é importante destacar Dejours (1986 ) ao defender que é a partir da compreensão das condições de trabalho que se pode compreender o que se passa na sociedade e nos indivíduos, em sua saúde física e mental, ou seja, para se conhecer o indivíduo, precisa-se conhecer o seu trabalho. Desse modo, compreendemos que os processos de saúde-doença dos professores têm um conjunto de determinações sociais, políticas, culturais e individuais correlacionadas às condições de trabalho. 


\section{Cinerarius Rof em Educação. UFG - Regional Jatai \\ v. 11, n. 2,2015}

\section{CONSIDERAÇÕES FINAIS}

Os resultados obtidos no presente estudo revelam aspectos importantes sobre a relação entre as condições de trabalho e a saúde dos professores de escolas de Educação Básica no sudoeste goiano. O processo de trabalho na Educação Básica, no contexto estudado, permite uma sobrecarga e condições inadequadas de trabalho que, na maioria das vezes, contribuem para os problemas de saúde dos professores. As condições de trabalho apresentadas pelos docentes investigados, por si só, já são um indicativo de uma situação de precarização que pode levar o trabalhador à exaustão física e emocional. Ao depararmos com os problemas de saúde apresentados é possível compreender o elo entre a realidade vivida e o adoecimento docente.

Os dados apresentados são coerentes com resultados de pesquisas realizadas com a temática em literatura estudada. Desse modo, o estudo do processo de adoecimento dos professores deve, necessariamente, estar articulado à análise do processo de trabalho e sua condição de realização. A partir daí, torna-se possível apontar caminhos para a superação das dificuldades vivenciadas nas escolas de Educação Básica da atualidade.

\section{REFERÊNCIAS}

ALVES, W. F. A formação contínua e a batalha do trabalho real: um estudo a partir dos professores da escola pública de Ensino Médio. 2009. 343 p. Tese (Doutorado em Educação). Universidade de São Paulo: Faculdade de Educação. São Paulo, 2009.

AMORIM, S. N. M. de C. Distúrbio vocal e estresse: os efeitos do trabalho na saúde de professores/as do ensino fundamental de Goiânia. Universidade Católica de Goiás (Dissertação de mestrado): Goiânia, 2006.

AREIAS, M. E. Q.; GUIMARÃES, L.A.M. Gênero e estresse em trabalhadores de uma universidade pública do Estado de São Paulo. Psicologia em Estudo, Maringá, v. 9, n. 2, p. 255-262, mai./ago. 2004.

ASSUNÇÃO A. A.; OLIVEIRA D. O. Intensificação do trabalho e saúde dos Professores. Educ. Soc., Campinas, vol. 30, n. 107, p. 349-372, maio/ago. 2009.

BATISTA, A. S.; CODO, W. Crise de identidade e sofrimento. In.: CODO, W. (coord.). Educação: carinho e trabalho. Petrópolis-RJ: Editora Vozes, 1999.

BORGES, K. P. Trabalho e saúde dos trabalhadores da Educação Básica. Universidade Federal de Goiás, Faculdade de Educação (Dissertação de Mestrado). Goiânia, 2011. 183 f. 


\section{Tinerarius Rofotons

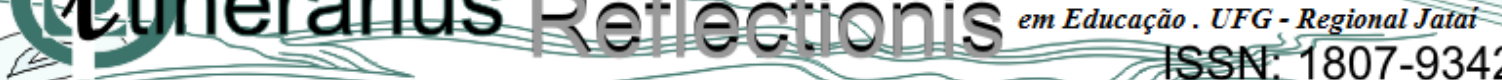 v. 11, n. 2,2015} 12

BRASIL. Lei de Diretrizes e Bases da Educação Nacional, Lei $N^{\circ} 9.394$, de 20 de dezembro de 1996.

CAMPOS, G.W.S. Clinica e saúde coletiva compartilhadas: teoria Paidéia e reformulação ampliada do trabalho em saúde. In CAMPOS, G. W. S. et. al.(org.)Tratado de saúde coletiva. São Paulo: Hucitec, 2006.

CANDAU, V. M. O/a educador/a como agente cultural. In: LOPES, A. R. C.; MACEDO, E. F. de; ALVES, M. P. C. Cultura e política de currículo. Araraquara: Junqueira e Marin, 2006.

CARVALHO, S.R. e CUNHA, G.T. A gestão da atenção na saúde: elementos para se pensar a mudança da organização na saúde (p. 837-868). In: CAMPOS, G.W.S. et. al. (org.) Tratado de saúde coletiva. São Paulo: Hucitec, 2006.

CODO, W. (coord.). Educação: carinho e trabalho. Petrópolis-RJ: Editora Vozes, 1999.

COSTA, K. E. Efeito da suplementação de cafeína sobre biomarcadores salivares e plasmáticos em ciclistas e praticante de spinning durante teste experimental em cicloergômetro. Universidade Federal de Uberlândia (dissertação) - Uberlândia, 2006.

CRUZ, R. M.; LEMOS, J. C.; WELTER, M. M.; GRUISSO, L. Saúde Docente, Condições e Carga e Trabalho. Revista Electrónica de Investigación y Docencia (REID), 4, Julio, 2010, 147-160.

DEJOURS, C. A loucura do trabalho: estudo e psicopatologia do trabalho. $6^{\mathrm{a}}$ ed. São Paulo: Cortez, 2015.

DEJOURS, C. Por um novo conceito de saúde. Revista Brasileira de Saúde Ocupacional. São Paulo, V. 14, n. 54, p. 7-11, 1986.

A carga psíquica do trabalho. In DEJOURS, C.; ABDOUCHELI, E.; JAYET, C. Psicodinâmica do Trabalho: contribuições da escola dejouriana à análise da relação prazer, sofrimento e trabalho. São Paulo: Atlas, 1994.

ESTEVE, J. M. Mudanças sociais e função docente. In: NOVOA, A. (org.). Profissão Professor. Portugal: Porto, 1999.

FERREIRA, L. L. Relação entre o trabalho e a saúde dos professores na Educação Básica no Brasil. FUNDACENTRO: São Paulo, 2010.

GASPARINI, S. M.; BARRETO, S. M.; ASSUNÇÃO, A. A. O professor, as condições de trabalho e os efeitos sobre sua saúde. Educação e Pesquisa, São Paulo, v. 31, n. 2, p. 189199, maio/ago. 2005.

GIL, A. C. Métodos e Técnicas de Pesquisa Social. $6^{\text {a }}$ ed. São Paulo: Atlas, 2008.

GÜNTHER, H. Pesquisa Qualitativa Versus Pesquisa Quantitativa: Esta É a Questão? Psic.: Teor. e Pesq., Brasília, Mai-Ago 2006, Vol. 22 n. 2, pp. 201-210 


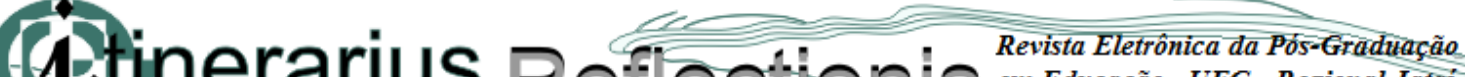 em Educação. UFG - Regional Jataí

JORGE, I. M. P. Doenças Psicossomáticas Relacionadas ao Trabalho: estudo de caso. Universidade Federal de Santa Catarina (Dissertação de mestrado). Florianópolis, 2004.

LIMA, M. F. E. M.; LIMA-FILHO, D. O. Condições de trabalho e saúde do/a professor/a universitário/a. Ciência \& Cognição 2009; vol. 14 (3): 62-82.

MORENO-JIMENEZ, B. et. al. A avaliação do burnout em professores. Comparação de instrumentos: cbp-r e mbi-ed. Psicologia em Estudo, Maringá, v. 7, n. 1, p. 11-19, jan./jun. 2002.

NAUJORKS, M. I. Stress e Inclusão: indicadores de stress em professores frente a inclusão de alunos com necessidades especiais. Cadernos de Educação Especial, Santa Maria-RS, vol.20, p. 117-125, 2002.

NOVOA, A. (org.). Profissão Professor. Portugal: Porto, 1999.

NOVOA, A. O regresso dos professores. Educa, Lisboa, Portugal, 2010.

NUNES SOBRINHO, F. de P. O stress do professor do ensino fundamental: o enfoque da ergonomia. In: LIPP, Marilda (Org.). O stress do professor. 7.ed. Campinas/SP: Papirus, 2012.

OLIVEIRA, D. A.; ASSUNÇÃO, A. A. Condições de Trabalho Docente. In:OLIVEIRA, D.A.; DUARTE, A.M.C.; VIEIRA, L.M.F. DICIONÁRIO: trabalho, profissão e condição docente. Belo Horizonte: UFMG/Faculdade de Educação, 2010. CDROM

OLIVEIRA, D. A. A Reestruturação do trabalho docente: precarização e flexibilização. Educação e Sociedade, V. 25, N 89, 2004.

OLIVEIRA, E. da S. G. O "mal-estar" docente como fenômeno da modernidade: os professores no país das maravilhas. Ciências \& Cognição 2006; vol. 7: 24-41

ROBALINO, M. A saúde e o trabalho na educação da América Latina. Revista Retratos da Escola, Brasília, v. 6, n. 11, p. 315-326, jul./dez. 2012.

SILVA, L. C. da. A LDB, as Políticas Públicas e a Formação de Professores: rumo ao paradigma da inclusão educacional? In: SILVA, M. V.; MARQUES, M. R. A. (orgs.). LDB: balanços e perspectivas para a educação brasileira. Campinas-SP: Editora Alínea, 2008.

SILVA, L. G. A. da. Contrato, carreira e remuneração docente em Goiás. In: OLIVEIRA, J. F.; OLIVEIRA, D. A.; VIEIRA, L. F. (org.). Trabalho Docente na Educação Básica em Goiás. Belo Horizonte, MG: Fino Traço, 2012.

VASQUES-MENEZES, I.; CODO, W.; MEDEIROS, L. O conflito entre o trabalho e a família e o sofrimento psíquico. In: CODO, W. (coord.). Educação: carinho e trabalho. Petrópolis-RJ: Editora Vozes, 1999. 